\title{
O SABER FAZER DOCENTE EM EDUCAÇÃO PARA A SEXUALIDADE NA EDUCAÇÃO BÁSICA: UM PARALELO ENTRE PORTUGAL E BRASIL
}

\author{
EL CONOCIMIENTO DOCENTE EN EDUCACIÓN PARA LA SEXUALIDAD EN LA \\ EDUCACIÓN BÁSICA: UN PARALELO ENTRE PORTUGAL Y BRASIL
}

\author{
TEACHER KNOW HOW IN EDUCATION FOR SEXUALITY IN BASIC EDUCATION: \\ A PARALLEL BETWEEN PORTUGAL AND BRAZIL
}

\author{
Marilia Frassetto de ARAUJO ${ }^{1}$ \\ Célia Regina ROSSI ${ }^{2}$ \\ Filomena TEIXEIRA ${ }^{3}$
}

RESUMO: A pesquisa teve por objetivo compreender a construção do saber-fazer docente no Ensino Fundamental II, com professores/as de diferentes áreas (ciências humanas, exatas e biológicas) em relação à forma como é trabalhada a educação para a sexualidade em 2 escolas públicas de Coimbra - Portugal e 2 escolas públicas de Piracicaba, estado de São Paulo - Brasil. Como base, foi utilizada a legislação vigente nos dois países. Em Portugal o que ampara é a lei $n^{\circ} .60 / 2009$, de 6 de agosto, que estabelece a aplicação da educação sexual nos estabelecimentos de ensino básico e do ensino secundário da rede pública e privada. No Brasil existem os Parâmetros Curriculares Nacionais - PCNs, que, tratando da educação para a sexualidade, tem como objetivo mediar informações e problematizar questões relacionadas à sexualidade, incluindo posturas, crenças, tabus e valores a elas associados. A atuação do tema da sexualidade na sala de aula visa propiciar aos/às jovens a possibilidade do exercício de sua sexualidade de maneira responsável, saudável e prazerosa. Então, levando em consideração a formação (inicial ou contínua) de professores/as e através de observação e entrevistas semiestruturadas com os mesmos/as, os/as quais foram o foco desta pesquisa, buscou-se compreender como pensam ser construída a educação para sexualidade.

PALAVRAS CHAVE: Educação para a sexualidade. Políticas de formação de professores. Relações de gênero. Fazer docente.

RESUMEN: La investigación tuvo por objeto comprender la construcción del conocimiento docente en la Enseñanza Primaria II, con profesores/as de diferentes áreas (ciencias humanas, exactas y biológicas) en relación a la forma en que se trabaja la educación para la sexualidad en 2 escuelas públicas de Coimbra - Portugal y 2 escuelas públicas de Piracicaba, estado de São Paulo - Brasil. Como base, se utilizó la legislación vigente en los dos países. En Portugal lo que ampara es la ley $n^{\circ}$ 60/2009 de 6 de agosto, que establece la aplicación de la educación sexual en los establecimientos de enseñanza básica y de la enseñanza secundaria de la red

\footnotetext{
${ }^{1}$ Universidade Estadual Paulista (UNESP), Araraquara - SP - Brasil. Doutoranda do Programa de Pós-graduação em Educação Escolar. ORCID: <http://orcid.org/0000-0001-7345-7253>. E-mail: Marilia.frassetto@ gmail.com ${ }^{2}$ Universidade Estadual Paulista (UNESP), Rio Claro - SP - Brasil. Profa. Dra. Instituto de Biociências. Departamento de educação. ORCID: <https://orcid.org/0000-0002-2903-4955>. E-mail: celiarr@ rc.unesp.br ${ }^{3}$ Escola Superior de Educação de Coimbra (ESEC), Coimbra - Portugal. Professora Coordenadora. ORCID: <https://orcid.org/0000-0001-7374-3671>. E-mail: filomena.tx@ gmail.com
} 
pública y privada. En Brasil hay los Parámetros Curriculares Nacionales - PCNs, que, tratando de la educación para la sexualidad, tiene como objetivo mediar informaciones y problematizar cuestiones relacionadas a la sexualidad, incluyendo posturas, creencias, tabús, y valores a ellas asociados. La actuación del tema de la sexualidad en el aula busca propiciar a los jóvenes la posibilidad del ejercicio de su sexualidad de manera responsable, sana y agradable. Por lo tanto, teniendo en cuenta la formación (inicial o continua) de profesores/as y mediante observación y entrevistas semiestructuradas con ellos, los cuales fueron el enfoque de esta investigación, se buscó comprender cómo piensan que se construye la educación para la sexualidad.

PALABRAS CLAVE: Educación para la sexualidad. Políticas de formación de profesores. Relaciones de género. Conocimiento docente.

ABSTRACT: The research was aimed to understand the construction of know-how of the teaching staff in Elementary Education II, with teachers from different areas (humanities, sciences and biological sciences) in relation to how the sexuality education was worked in 02 public schools in Coimbra - Portugal and in 02 public schools in Piracicaba, São Paulo Brazil. As a basis, we use the current legislation in both countries. In Portugal, the law that sustains it is the No. 60/2009 of August 06, establishing the implementation of sex education in primary and secondary schools, both public and private. In Brazil there is the National Curricular Parameters - PCNs, which dealing with sexuality education, aims to mediate information and problematize issues related to sexuality, including attitudes, beliefs, taboos, and values associated with them. The acting of the theme of sexuality in the classroom aims to provide young people the possibility to exercise their sexuality in a responsible, healthy and pleasant way. Then, taking into account the teachers formation (initial or continuing) and through observation and semi-structured interviews with them, which are the focus of this project, we could understand how the education for sexuality was built for them.

KEYWORDS: Sexuality for education. Teachers formation policies. Gender relations. Teaching staff know-how.

\section{Introdução}

Este artigo ${ }^{4}$ é derivado de uma pesquisa intitulada "O fazer docente na educação para a sexualidade em Coimbra - Portugal e Piracicaba - SP - Brasil: realidades de 04 escolas de ensino básico", financiada pelo Fundo de Amparo à Pesquisa do Estado de São Paulo FAPESP, processo 11/12902-3.

A pesquisa se deu a partir de entrevistas com professores/as de quatro escolas de diferentes contextos, sendo duas da cidade de Coimbra, Portugal e duas da cidade de Piracicaba, SP, Brasil, e discutiu as informações mais relevantes e com conteúdos mais pertinentes a fim

${ }^{4}$ Este trabalho foi apresentado e teve resumo publicado nos Anais do II CISES - II Congresso Internacional De Sexualidade e Educação Sexual de Araraquara, p. 115-116. 
de compreender o saber-fazer docente, tomando conhecimento de quais aspectos da educação para a sexualidade e relações de gênero eram mais beneficiados no dia-a-dia do/a professor/a dessas escolas.

Atualmente, os entendimentos sobre sexo e sexualidade emergiram e estão em destaque, assim como alguns valores que estabeleceram novos comportamentos a serem seguidos através da linguagem, da moda e até das maneiras de se relacionar (SOARES, 2013).

Por esses fatores, percebe-se a importância de que a temática seja problematizada e discutida em contexto escolar. Debora Britzman (2001) afirma que a cultura da escola permite que o ensino seja mais importante do que o entendimento de questões íntimas, e que nessa cultura as possibilidades de novas questões e desenvolvimento da curiosidade não acontecem, o que faz o campo da sexualidade ser deixado para segundo plano, um espaço de respostas certas ou erradas.

O espaço pedagógico é segregado em dois períodos, sendo um referente ao processo de ensino e aprendizagem e outro à preocupação da escola com assuntos relacionados a valores morais e comportamento, o segundo, relegado pela instituição escolar como um todo. "A escola não considera e/ou muitas vezes desconhece as práticas corporais dos jovens que transitam por seus espaços" (AMARAL; DOMINGUES; SILVA, 2013, p. 25).

Entretanto, as autoras acima afirmam ainda que é na escola que os/as alunos/as têm a oportunidade de vivenciar e trocar experiências, e que as necessidades deles/as, por mais que sejam reprimidas, vão surgir e se sobrepor às normas.

Partindo dessa premissa, pode-se entender que os/as professores/as devem levar o assunto para as salas de aula.

Segundo Louro, a sexualidade é construída, ao longo de toda a vida, de diversos modos, por todos os sujeitos.

A sexualidade envolve rituais, linguagens, fantasias, representações, símbolos, convenções... Processos profundamente culturais e plurais. [...] as possibilidades da sexualidade - das formas de expressar os desejos e prazeres - também são sempre socialmente estabelecidas e codificadas (LOURO, 1999, p. 26).

Para Britzman (1996), a sexualidade desencadeia o desejo de aprender, a curiosidade, desencadeia o ato de tornar-se um cidadão ou cidadã. Entretanto, na escola,

[...] quando chega a ser tratado, o conhecimento de sala de aula sobre sexualidade é tipicamente sinônimo de reprodução heterossexual, embora até mesmo esse conhecimento seja banalizado. Além disso, a assim chamada informação técnica sobre reprodução sexual é altamente contestada porque a 
informação sobre sexo é vista como a causa da atividade sexual (BRITZMAN, 1996, p. 78).

Sobre as relações de gênero, é necessário considerar as maneiras como o gênero é representado, pois essas representações podem estabelecer diferenças e identidades que colocam cada sujeito em uma determinada classificação.

Para Joan Scott (1990), o gênero é uma categoria útil à história da sociedade e não apenas à história das mulheres. A autora propõe um uso do gênero muito mais abrangente, afirmando que o gênero é um elemento constitutivo de relações sociais baseado nas diferenças percebidas entre os sexos, e que, além disso, é uma forma primeira de significar as relações de poder. Portanto, o termo gênero alude aos processos culturais que agem por intermédio das relações de poder, construindo padrões hegemônicos, a partir de corpos sexuados.

O termo "gênero" torna-se, antes, uma maneira de indicar "construções culturais" - a criação inteiramente social de ideias sobre papéis adequados aos homens e às mulheres. Trata-se de uma forma de se referir às origens exclusivamente sociais das identidades subjetivas de homens e de mulheres. "Gênero" é, segundo essa definição, uma categoria social imposta sobre um corpo sexuado. Com a proliferação dos estudos sobre sexo e sexualidade, "gênero" tornou-se uma palavra particularmente útil, pois oferece um meio de distinguir a prática sexual dos papéis sexuais atribuídos às mulheres e aos homens (SCOTT, 1990, p. 75).

É possível compreender a identidade de gênero como a autopercepção de cada indivíduo em relação às categorias sociais que se referem ao masculino e ao feminino e a uma representação biológica, construída por fatores sociais e culturais que são predominantes na formação humana. O desenvolvimento da identidade ocorre desde o nascimento, em uma constante troca entre o sujeito e os outros, de maneira móvel e mutável (LOURO; RIBEIRO, 1997, 2002).

Dagmar Meyer (2003) aponta que os gêneros são como "produtos" criados a partir do âmbito social, cultural, histórico e linguístico, que decorre das relações de poder, compreendendo os processos que produzem e afastam os corpos dotados de sexo, gênero e sexualidade. Já Ribeiro e Soares (2013) sintetizam que o conceito de gênero ocorre a partir de construções culturais, produzidas historicamente com princípio nas características de natureza biológica dos corpos. Além disso, as autoras ressaltam que,

[...] os gêneros se fazem e se refazem, continuamente, ao longo de sua existência. [...] há uma multiplicidade de construções do ser masculino e do ser feminino, pois diversificados modelos ideais, padrões e imagens, de diferentes contextos (classes, raças, etnias, nacionalidade, religião) configuram o processo de formação do homem e da mulher (RIBEIRO; SOARES, 2013, p. 26). 
No ambiente escolar, segundo Ribeiro e Soares (2013), algumas situações como filas, grupos de trabalho, atividades físicas e brincadeiras são separados por sexo, considerados como "de menino" ou "de menina", o que reforça essa distinção social.

Sobre as relações de gênero no espaço escolar, o assunto também é de pouca relevância entre os/as professore/as. O olhar dos/as funcionários/as (direção, professores/as, coordenação, e os/as demais) não é sensível para essa temática no cotidiano escolar. Isso se dá talvez pela dificuldade de refletir e problematizar, além das desigualdades entre os sexos, mas também os significados de gênero implícito a essas desigualdades e pouco considerados pelas políticas públicas que regem o sistema educacional (VIANNA; UNBEHAUM, 2004).

Em Portugal a primeira legislação sobre a educação sexual nas escolas se deu através da Lei $n^{\circ} .3 / 84$, de 24 de março de 1984.

Após alguns inúmeros decretos, foi elaborado o decreto lei nº. 60/2009, de 06 de agosto, regulamentado pela portaria 196-A de 09 de abril de 2010, que estabelece a aplicação da educação sexual nos estabelecimentos de ensino básico e do ensino secundário. Esta lei tem diversas finalidades, entre elas:

\begin{abstract}
A valorização da sexualidade e afetividade entre as pessoas no desenvolvimento individual, respeitando o pluralismo das concessões existentes na sociedade portuguesa; A redução de consequências negativas dos comportamentos sexuais de risco, tais como a gravidez não desejada e as infeções sexualmente transmissíveis; $O$ respeito pela diferença entre as pessoas e pelas diferentes orientações sexuais; A promoção da igualdade entre os sexos;
\end{abstract}

Além das finalidades, esta lei também define (até os dias de hoje) a carga horária mínima que deve ser utilizada na educação sexual. Dessa forma, a educação em sexualidade foi adaptada a cada nível de ensino e a cada turma, e não é inferior a 6 horas para o $1 .^{\circ}$ e $2 .^{\circ}$ ciclos do ensino básico, nem inferior a 12 horas para o $3 .^{\circ}$ ciclo do ensino básico e secundário, distribuídas de forma equilibrada pelos diversos períodos do ano letivo.

No Brasil, após o surgimento dos Parâmetros Curriculares Nacionais - PCNs, organizados pelo Ministério da Educação do Brasil, com o propósito de ser uma proposta curricular que desse amparo aos conhecimentos trabalhos nas diferentes áreas, ciências sociais e humanas, ciências biológicas e exatas, ocorreu a necessidade de incorporar assuntos sociais atuais, necessários para a melhor entendimento e formação do/a aluno/a. Surgiram assim os temas transversais, que têm no seu bojo a educação sexual, entre outras temáticas da atualidade.

O tema transversal é concebido em todas as áreas do conhecimento escolar, e a Orientação Sexual passa também a ser interiorizado nas disciplinas, cooperando para que não 
ocorra uma fragmentação curricular, pois oferece a integração desse conhecimento em todo contexto escolar.

[...] tanto a concepção quanto os objetivos e conteúdos propostos por Orientação Sexual encontram-se contemplados pelas diversas áreas do conhecimento. Dessa forma, o posicionamento proposto pelo tema de orientação sexual, assim como acontece com todos os temas transversais, estará impregnando toda a prática educativa. Cada uma das áreas tratará da temática da sexualidade por meio da sua própria proposta de trabalho (PCN, 1997b, p. 128).

Os PCNs (1997) afirmam que a orientação sexual na escola deve ser entendida como um processo de intervenção pedagógica, que tem como objetivo mediar informações e problematizar questões relacionadas à sexualidade, incluindo posturas, crenças, tabus e valores a elas associados. A atuação do tema da sexualidade na sala de aula visa propiciar aos jovens a possibilidade do exercício de sua sexualidade de maneira responsável, saudável e prazerosa.

Além disso, segundo documento Orientações técnicas de educação em sexualidade para o cenário brasileiro: tópicos e objetivos de aprendizagem (2014), da UNESCO,

A educação em sexualidade pode ser entendida como toda e qualquer experiência de socialização vivida pelo indivíduo ao longo de seu ciclo vital, que lhe permita posicionar-se na esfera social da sexualidade. A educação em sexualidade está presente em todos os espaços de socialização - família, escola, igreja, pares, trabalho, mídia -, mas ocorre de forma pulverizada, fragmentada e desassociada de um plano de sociedade inclusiva baseada nos direitos humanos. Portanto, torna-se relevante a atuação do sistema educacional na tarefa de reunir, organizar, sistematizar e ministrar essa dimensão da formação humana.

Entretanto, é importante salientar que no Brasil a temática da sexualidade não é obrigatória nas instituições escolares, mas sim é apontada como recomendada, via os PCNs e Orientações técnicas de educação em sexualidade para o cenário brasileiro: tópicos e objetivos de aprendizagem.

\section{Abordagem metodológica}

A pesquisa utilizou-se da abordagem qualitativa por considerar de grande importância o ato de vivenciar aspectos do cotidiano do/a professor/a, da sua subjetividade. Para a coleta de dados foram realizadas entrevistas semiestruturadas com cinco professores/as das diferentes áreas de cada escola, no Brasil e em Portugal.

Para a análise dos dados foi utilizada a análise de conteúdo, extraindo das categorias elencadas previamente as subcategorias, a partir dos dados coletados em campo; para além das 
entrevistas, a pesquisadora criou blocos de notas, pontuando observações para analisar os fatos mais relevantes do conteúdo das entrevistas.

A pesquisa teve o cuidado em não divulgar os nomes e nem o sexo dos/as entrevistados/as, a fim de que não houvesse a sua exposição. Houve também por parte da pesquisadora o cuidado de enviar um termo de consentimento livre e esclarecido, com toda a estrutura e percurso da pesquisa.

Foram utilizadas as iniciais das escolas para identificá-las durante a análise dos dados: RSI (Coimbra, Portugal); MF (Coimbra, Portugal); EAC (Piracicaba - SP, Brasil); EJC (Piracicaba - SP, Brasil).

\section{Análise e discussão dos dados}

A pesquisadora organizou quadros subdivididos nas categorias que foram elencadas para se extrair as subcategorias, que continham os discursos mais significativos das falas dos/as professores/as entrevistados/as.

As categorias extraídas foram: Conhecimento da lei; Importância da lei; Significado e importância da sexualidade e das relações de gênero; Formação em Sexualidade; Sexualidade e Relações de Gênero nas Disciplinas; Aspectos da sexualidade na sala de aula;

A respeito do conhecimento dos/as docentes entrevistados/as sobre o decreto lei $\mathrm{n}^{\circ}$. 60/2009 em Portugal e os PCNs no Brasil, a maioria afirmou conhecê-los: tanto em Coimbra quanto em Piracicaba houve somente um/a professor/a que referiu desconhecer a legislação. A negação e a ausência aparecem, nesse caso, como uma espécie da garantia da "norma" (LOURO, 2001, p. 89).

Entretanto, apesar da maioria ter conhecimento sobre o que ampara a educação para a sexualidade, foi possível observar que nem todos/as se sentiam aptos/as e possuíam formação suficiente para trabalhar a temática.

Sobre os/as educadores/as, Britzman (1996, p. 92) afirma que,

Se os/as educadores/as quiserem ser eficazes em seu trabalho com todos/as os/as jovens, eles/elas devem começar a adotar uma visão mais universalizante da sexualidade em geral e da homossexualidade em particular. Assim, em vez de ver a questão da homossexualidade como sendo de interesse apenas para aquelas pessoas que são homossexuais, devemos considerar as formas como os discursos dominantes da heterossexualidade produzem seu próprio conjunto de ignorâncias tanto sobre a homossexualidade quanto sobre a heterossexualidade. 
Sobre a importância da lei, os/as professores/as portugueses/as concordaram que a informação sobre sexualidade é essencial na educação para a saúde, apesar de alguns/umas professores/as da escola MF portuguesa terem dito que tal lei não é cumprida como deveria ser. Vale destacar que os/as professores/as olham, na maioria das vezes, para a sexualidade apenas como um conhecimento biológico e da saúde. Retomar-se-á esta perspectiva mais adiante.

Quanto aos PCNs, os/as professores/as brasileiros/as afirmaram a sua importância como essencial para os/as alunos/as adquirirem determinados conhecimentos, como o próprio corpo, questões relacionadas à homossexualidade, ao machismo, entre outras.

Outro fator importante é demonstrado na Categoria "Significado e Importância da Sexualidade e das Relações de Gênero", a qual gerou diferentes respostas. Os/as professores/as tiveram muita dificuldade em responder e esclarecer.

Pode-se perceber que os/as professores/as da área de humanas (ciências sociais e humanas), tanto de Portugal quanto do Brasil, concordaram na importância da educação para a sexualidade, e que este é um tema que todos/as poderiam e deveriam tratar, de acordo com a disciplina e as oportunidades de se tocar no assunto dentro da sala de aula. No entanto, mesmo com essas respostas positivas, notou-se ainda falas carregadas de preconceitos, modos de exclusão, como a de professores/as brasileiros/as da EJC, quando citam o "diferente".

Quanto às disciplinas de ciências biológicas e ciências exatas, os/as professores/as também abordaram a importância do assunto e também a importância de sanar as dúvidas dos alunos/as, tendo em vista que muitos/as deles/as levavam informações equivocadas para o ambiente escolar. Entretanto, alguns/umas professores/as afirmaram não se sentirem preparados/as para falar sobre a temática, e referiram acreditar que o mais indicado seria que tivessem mais formação para tal trabalho, ou então que fossem apenas os/as professores/as de ciências a trabalhar a educação para a sexualidade.

Quanto às relações de gênero, em todas as escolas, percebeu-se que somente os/as professores/as da área das ciências e alguns/umas da área de humanas trabalhavam com a temática. Segundo Vianna e Unbehaum (2004, p. 79)

Nas escolas, as relações de gênero também ganham pouca relevância entre educadores e educadoras, assim como no conteúdo dos cursos de formação docente. Ainda temos os olhos pouco treinados para ver as dimensões de gênero no dia a dia escolar, talvez pela dificuldade de trazer para o centro das reflexões não apenas as desigualdades entre os sexos, mas também os significados de gênero subjacentes a essas desigualdades e pouco contemplados pelas políticas públicas que ordenam o sistema educacional. 
Percebe-se, assim, que a escola designa a tarefa de sexualidade ainda para professores/as das áreas de saúde e de ciências, olhando assim a sexualidade como um tema somente de cunho biológico, descartando o cunho social, político, econômico e cultural, em que professores/as de diferentes conhecimentos poderiam compor com suas áreas de atuação, mostrando que a sexualidade está em todos os campos.

Fazendo uma análise da lei $\mathrm{n}^{\circ}$. 60/2009, percebe-se que a palavra gênero aparece somente duas vezes. Ambas as vezes quando se fala nos "objetivos mínimos que a área de educação sexual deve contemplar", na qual "gênero" está inserido no $3^{\circ}$ e $4^{\circ}$ ano da seguinte forma, "[...] caso os alunos se deparem com dúvidas ou problemas de identidade de gênero, se sintam no direito de pedir ajuda às pessoas em quem confiam na família ou na escola". E posteriormente está inserido como um dos conteúdos a serem trabalhados no $2^{\circ}$ ciclo $\left(3^{\circ}\right.$ e $4^{\circ}$ ano), no tópico "Sexualidade e Gênero".

Já nos Parâmetros Curriculares Nacionais, a palavra gênero aparece constantemente, dentre outras formas, ligada a estereótipos, à violência, à convivência escolar, e também à perspectiva de gênero em si.

Para Costa e Ribeiro (2008), quando docentes "optam por discutir as questões sexuais em aulas de educação física e ciências, que remete à ideia de que a sexualidade é essencialmente biológica e está voltada para a prevenção de doenças sexuais e reprodução humana".

Guacira Louro (1997, p. 21) afirma que

[...] é necessário demonstrar que não são propriamente as características sexuais, mas é a forma como essas características são representadas ou valorizadas, aquilo que se diz ou se pensa sobre elas, que vai constituir, efetivamente, o que é feminino ou masculino em uma dada sociedade e em um dado momento histórico.

$\mathrm{Na}$ escola portuguesa MF o/a professor/a de ciências ressaltou que não se pode ter a mentalidade de que a mulher não pode fazer algo ou que tal atividade seja restrita ao homem, e que, dessa forma, procurava garantir a igualdade e equidade de gênero com seus alunos e alunas.

As relações de gênero na escola têm pouco espaço, no trabalho com os/as alunos/as tal conceito é pouco valorizado e pode-se afirmar que é pouco reconhecido, que muitas vezes o/a professor/a não enxerga essas questões, por isso não as aborda.

Na categoria a Formação em Sexualidade nota-se que "a partir do momento em que se inicia o ensino do conteúdo de sexualidade, surge, paralelamente, a necessidade de buscar formas mais adequadas para o ensino desse conteúdo devido às particularidades que ele impõe" (CARVALHO e SILVA, 2005 p. 78). 
A maioria dos/as professores/as da área de humanas de Coimbra tiverem mais formação continuada e uma formação mais completa. Já entre os/as professores/as de humanidades do Brasil, nenhum relatou formação específica para trabalhar a educação para a sexualidade. Relataram somente estudos pessoais para poderem abordar o tema com mais segurança.

$\mathrm{Na}$ área de ciências biológicas, todos/as os/as professores(as) de ciências, de Portugal e do Brasil, afirmaram ter recebido a formação durante a graduação, mas nada específico sobre a educação para a sexualidade na escola, o cunho era mais biológico. Os/as professores/as de educação física relataram não ter tido formação durante a graduação.

Quanto à formação inicial ou contínua, os/as professores/as das ciências exatas afirmaram nunca terem tido qualquer tipo de formação. Os/as professores/as das 2 escolas portuguesas disseram que trabalhavam com o auxílio do CAOJ nas aulas de formação cívica. Já os/as professores/as brasileiros/as procuravam trabalhar de forma natural, sanar as dúvidas dos/as alunos/as de acordo com o conhecimento que já tinham, que traziam de suas vidas pessoais

Entre as quatro escolas, através dos discursos dos/as protagonistas, foi possível observar que a escola RSI (Portugal) e EAC (Brasil), ambas localizadas na periferia, realizaram algumas parcerias e os/as docentes se envolveram mais com a temática, tiveram mais formação e, de maneira geral, se sentiam mais preparados/as para trabalhar o tema, enquanto os/as professores/as da MF (Portugal) tiveram apenas algumas horas de formação oferecida pela escola e ainda não as consideravam como sendo suficiente para suprir as necessidades dos/as alunos/as. Os/as professores/as da EJC (Brasil), que afirmaram não ter formação, relataram somente sobre sua atuação, sem citar a participação da ONG.

Também houve professores/as dos dois países que admitiram que o tema da sexualidade aparece em suas aulas, mas que sentiam dificuldade em trabalhá-lo devido à pouca ou nenhuma formação.

Pelas análises evidencia-se que os/as professores/as trazem um conhecimento, uma experiência, que forma sua identidade, e este conhecimento somado à formação torna um saber único, original, permeado de crenças, valores e moral. Sendo assim, é importante reconhecer que existe a pluralidade e a heterogeneidade dos/as professores/as por conta das diferentes vivências.

Segundo Tardif (1991, p. 234),

[...] o(a)s professor(a)s tentam transformar suas relações de exterioridade com os saberes em relações de interioridade com sua própria prática. Nesse sentido os saberes da experiência não são saberes como os demais, eles são, ao 
contrário, formados de todos os demais, porém retraduzidos, "polidos" e submetidos às certezas construídas na prática e no vivido.

Essa tendência de transformar os saberes pode ser relevante ou irrelevante, por que o/a professor/a pode ter uma visão mais abrangente e sem preconceitos, ou então ao contrário, ser carregado de estereótipos e acabar por incutir nos/as alunos/as sua forma de pensar. Reforçase, assim, a importância da formação inicial ou contínua para o saber fazer docente.

Na categoria "Sexualidade e Relações de Gênero nas Disciplinas", os/as professores/as relataram brevemente a forma como introduziam os assuntos em sala de aula, quando se tratava do seu conhecimento específico, ou seja, na disciplina que trabalhavam. Para Louro (1997, p. 81):

Essa presença da sexualidade independe da intenção manifesta ou dos discursos explícitos, da existência ou não de uma disciplina de "educação sexual", da inclusão ou não desses assuntos nos regimentos escolares. A sexualidade está na escola porque ela faz parte dos sujeitos, ela não é algo que possa ser desligado ou algo do qual alguém possa se "despir".

É significativo perceber como as disciplinas de ciências sociais e humanas e de ciências exatas, de ambos os países, envolviam as questões referentes à sexualidade, reafirmando que não é somente nas disciplinas de ciências (biológicas) que é possível tratar o assunto. Em história, por exemplo, todos/as os/as professores/as entrevistados/as falaram sobre como abordavam o tema através das civilizações do passado. O/a professor/a aproveitava para trabalhar o papel da mulher na sociedade naquele tempo e como a mulher é tratada atualmente e também através dos adereços utilizados pelos reis durante as monarquias, rompendo assim tabus, e abordando a homossexualidade de forma não preconceituosa.

Na escola portuguesa RSI, o/a professor/a de matemática também abordava a questão ao falar de ciclos e períodos, assuntos que relacionava com o ciclo menstrual da mulher.

Segundo Costa e Ribeiro (2008), "a sexualidade se constitui mais como um elemento em transformação, cuja base, a cultura, a coloca em contato constante com instituições e discursos historicamente construídos". Com esta afirmação, entende-se a sexualidade como um tema transversal, passível de ser discutido em qualquer disciplina, que depende somente da habilidade e da forma como o/a professor/a a conduz.

$\mathrm{Na}$ categoria "Aspectos da Sexualidade na sala de aula", os/as protagonistas desta pesquisa falaram sobre o tema que mais beneficiavam e enfatizavam na sala de aula com referência à sexualidade. 
Todos/as os/as professores/as portugueses/as e brasileiros/as de ciências biológicas afirmaram debruçarem-se mais sobre as questões biológicas, os sistemas reprodutores masculino e feminino, a gravidez precoce e as doenças sexualmente transmissíveis.

No entanto, com as entrevistas semiestruturadas, o que foi possível perceber é que os/as professores/as de ciências sociais e humanas e de ciências exatas de Portugal, quando tinham oportunidade em sua disciplina ou na aula que ministravam de formação cívica, trabalhavam muito sobre a questão dos afetos, exploravam os sentimentos de amor, amizade, do respeito mútuo, a aceitação de si mesmo e do próximo e queriam mostrar que sexualidade não é somente sexo, que é uma vivência, que tudo envolve sexualidade.

Já os/as docentes de ciências sociais e humanas e de ciências exatas do Brasil, privilegiavam em especial a prevenção às doenças sexualmente transmissíveis e as relações entre meninos e meninas, ou seja, as relações de gênero, com foco mais biológico.

Levando em conta a forma como estes/as disseram trabalhar a temática, analisando a fala destes/as docentes, e refletindo sobre o saber fazer docente, pode-se afirmar que eles/as

[...] revelaram que esse interesse se relaciona ao reconhecimento das necessidades evidenciadas pelos alunos de discutirem sobre sexualidade e, também, à crença de que esse conteúdo ajudará na formação de indivíduos capazes de tomadas de decisões adequadas a um desenvolvimento biopsicossocial saudável. Outro aspecto que também as influenciou a ensinarem esse conteúdo foi a disposição para um repensar de suas próprias vidas. Assim, mesmo sem possuir uma formação específica para o ensino de tal conteúdo, elas vislumbraram a possibilidade de ministrar aulas eficazes devido à experiência de ensino que já possuíam (CARVALHO; SILVA, 2005, p. 80).

E, certamente, quando os/as professores/as começam a trabalhar esse tópico, percebem o quanto é necessário procurar informações, se atualizarem e passam a buscar palestras, trocar informações com docentes que também abordam este tema, e o incentivo surge das próprias situações levantadas em sala de aula. Essa é uma busca interminável, pois sempre estão a surgir novos métodos, novos materiais e o/a professor/a tem que buscar o que mais se adequa a sua realidade escolar.

\section{Considerações finais}

Nota-se por meio desta pesquisa, tanto em Portugal como no Brasil, o valor de se trabalhar cada turma como sendo única e peculiar, levando em consideração o contexto familiar, econômico, histórico, educacional, social, fatores estes que influenciam a forma como o/a aluno/a traz e interioriza a sexualidade e a forma como o/a professor/a aborda o tema. 
Através das categorias analisadas pode-se desvelar que o saber fazer docente na educação para a sexualidade nas escolas RSI e MF, em Coimbra, Portugal e nas escolas EAC e EJC, em Piracicaba, SP-Brasil, está pautado na busca de novos saberes, de novos significados, de novas cartografias que se (re)constroem cotidianamente, por meio de novo fazer docente, empurrados, seja pela legislação vigente como a lei $n^{\circ}$. 60/2009, em Portugal, ou através dos parâmetros curriculares nacionais, no Brasil, ou ainda, pela atuação das $\mathrm{ONGs} \mathrm{CAOJ}^{5}$ e $\mathrm{CASVI}^{6}$, mas o mais significativo, é a possibilidade do/a professor/a atrever-se na busca de novas subjetividades, para uma melhor compreensão da sexualidade e das relações de gênero, e buscá-las por meio de formação qualificada.

Há relevância em pontuar que a maioria dos/as professores/as considerava o tema muito atual, importante dentro da escola, e quando surgiam momentos para tal, trabalhavam a educação para a sexualidade com os/as alunos/as, o que mostra que existe o desejo e a implicação, mas falta a formação adequada e qualificada.

É importante ressaltar que nas aulas de formação cívica, em Portugal, o assunto era sempre trabalhado e também na semana da sexualidade na EAC (Brasil), que se mostrou sempre engajada na busca de novas informações, parcerias, contribuições para alunos/as e professores/as.

Mas, além disso, a pesquisa apontou que muitos/as professores/as se ressentiam em trabalhar com a temática da sexualidade, por não se sentirem completamente preparados/as para tal feito, mas mesmo assim atuavam, por sentirem a necessidade de possibilitar outros olhares sobre a temática aos/às alunos/as, destacando assim a necessidade de formação e o interesse de que ela entre na escola.

Como já foi apontando anteriormente, a atuação do CAOJ nas escolas portuguesas permitiu formação a professores/as que a não possuíam, através da experiência vivenciada com a ONG. Enquanto o CASVI realizou trabalhos de formação aos/às professores/as durante alguns ATPCs $^{7}$ antes de ocorrer a semana da sexualidade na escola EAC.

Vale destacar que os/as professores/as que referiram atitudes mais positivas quanto à temática são os/as que participaram de formações anteriores. Já os/as que realizaram atividades e dinâmicas sobre sexualidade em suas aulas, os/as que são mais engajados nos projetos de intervenção e conhecem mais sobre a realidade da escola e dos/as alunos/as, são os que passaram por formações específicas e ela adentrou a sala de aula.

\footnotetext{
${ }^{5}$ CAOJ - Centro de Aconselhamento e Orientação de Jovens

${ }^{6}$ CASVI - Centro de Apoio e Solidariedade à Vida

${ }^{7}$ ATPC - Aula de Trabalho Pedagógico Coletivo
} 
Apesar dos resultados com este estudo respeitarem apenas a duas escolas de Coimbra e duas de Piracicaba, não podendo ser generalizados para todas as instituições escolares de Portugal e Brasil, o certo é que constituem um contributo para comparar e entender a realidade da educação para a sexualidade entre o que diz a lei e como esta se operacionaliza em sala de aula.

Além disso, os dados revelam que as atitudes dos/as professores/as na sala de aula podem variar, ou seja, são passíveis de mudanças, tendo em vista que podem decorrer de variáveis como maior nível de formação, maior envolvimento com os/as alunos/as, maior experiência e com o fato de possuir mais prática no decorrer dos anos, é um saber fazer que tende a progredir.

Entre as áreas de ciências sociais e humanas, biológicas e exatas, nos dois países, percebeu-se que na área de ciências humanas o trabalho era muito bem elaborado, os/as docentes estavam preparados/as, e abordaram o assunto interligando as relações de gênero com a temática da sexualidade.

$\mathrm{Na}$ área de ciências biológicas, os/as docentes tiveram formação durante a graduação no que se trata de reprodução, corpo humano, métodos contraceptivos, entre outros, então já possuíam determinada familiaridade com o tema, dentro de uma visão biológica de sexualidade. Sobre as outras questões que a sexualidade envolve como afetos, amizade, gênero, entre outros, eles/as também tratavam quando oportuno.

$\mathrm{Na}$ área de ciências exatas, os/as professores/as responsáveis pelas disciplinas também consideravam o assunto importante e disseram estar sempre disponíveis para solucionar qualquer dúvida. Um/a deles/as contou conseguir relacionar um-assunto da matemática com um referente à sexualidade. Percebe-se que os/as professores/as buscam sozinhos meios de atender a demanda dos alunos/as, poucos aludem que a temática foi trabalhada na formação inicial ou contínua.

Através da análise dos dados percebeu-se também como é complexo o saber-fazer docente, e que nas quatro escolas, de Coimbra e de Piracicaba, o trabalho vem sendo desempenhado com competência, responsabilidade e busca de novas práticas. Entretanto, a maioria dos/as professores/as gostaria de ter uma formação mais adequada e qualificada para abordar a temática, devido o assunto ser rodeado de preconceitos, tabus e equívocos.

É importante ressaltar que em Portugal, a lei em vigor, $n^{\circ}$ 60/2009, estabelece que a educação sexual esteja presente em todas as escolas, fornecendo bases para que o trabalho se realize. Assim, a lei portuguesa realmente institui que a temática seja trabalhada nas salas de aula. No Brasil o que temos ainda são "referências nacionais comuns ao processo educativo em 
todas as regiões brasileiras" (BRASIL, 1998, p. 6), ou seja, os PCNs apenas norteiam o trabalho do/a docente.

É imprescindível pontuar que os "sucessos e fracassos" em relação ao trabalho com a temática no contexto escolar são parte do processo de mudança histórica, cultural e de uma política educacional, que sobrecaem ainda no/a professor/a.

Para que haja um trabalho na escola com a temática da sexualidade e relações de gênero, são necessárias mudanças no que se refere às questões como: ampliação do financiamento educacional; melhoria de condições de trabalho dos/as professores/as e demais profissionais; carga horária efetiva destinada para planejamento, elaboração de material, reflexão, formação contínua. É importante também que formação inicial contemple estas temáticas, articuladas com outros assuntos que surgem na escola.

Vale enfatizar que a educação sexual é uma temática social urgente, mas deve ocorrer por meio de um trabalho durante toda a vida, começando pelas famílias e por toda a seriação escolar, contínua, intencional, sistemática e crítica, para que os/as jovens possam ressignificar de maneira criteriosa e autônoma as questões com as quais se deparam durante toda sua vida. As políticas educacionais são importantes instrumentos para que a temática da sexualidade e relações de gênero possam ocorrer na escola e assim se multiplicar em todas as comunidades, para avanço de uma sociedade mais equitativa e digna e com mais qualidade.

\section{REFERÊNCIAS}

AMARAL, A.; DOMINGUES, J. V.; SILVA, M. R. S.; Escola, Juventude e Corpos Modificados. In: RIBEIRO, Paula Regina Costa; QUADRADO, Raquel. (Org.). Corpos, Gêneros e Sexualidades: questões possíveis para o currículo escolar. 3. ed. Rio Grande: Editora da FURG, 2013.

BRASIL. Parâmetros curriculares nacionais: apresentação dos temas transversais, ética/Secretaria de Educação Fundamental. - Brasília: MEC/SEF, p. 146, 1997. Disponível em: http://portal.mec.gov.br/seb/arquivos/pdf/livro081.pdf.

BRASIL. Secretária de Educação Fundamental. Parâmetros Curriculares Nacionais: $3^{\circ}$ e $4^{\circ}$ Ciclos: Apresentação dos Temas Transversais. Brasília: MEC/SEF, p. 436, 1998.

BRITZMAN, D. O que é esta coisa chamada amor: identidade homossexual, educação e currículo. Revista Educação \& Realidade, Porto Alegre, v. 21, n. 1, p. 71-96, 1996.

BRITZMAN, D. Curiosidade, sexualidade e currículo. In: LOURO, G. L. (Org.). O Corpo Educado. 2. ed. Belo Horizonte: Autêntica, p. 35-82, 2001. 
CARVALHO, W. L. P.; SILVA, M. P. O desenvolvimento do conhecimento pedagógico do conteúdo de sexualidade na vivência das professoras. Ciência \& Educação, v. 11, n. 1, p. 7382,2005

COSTA, A. P.; RIBEIRO, P. R. M. Sexualidade e Relações de Gênero: a formação docente em questão. Gênero e sexualidade nas práticas escolares, São Paulo, 2008.

LOURO, G. L. Gênero, sexualidade e educação: uma perspectiva pós estruturalista. Petrópolis: Vozes, 1997.

LOURO, G. L. Pedagogias da sexualidade. In: . (Org.). O corpo educado pedagogias da sexualidade. Belo Horizonte: Autêntica, 1999.

LOURO, G. L. O currículo e as diferenças sexuais e de gênero. In: COSTA, M.V. (Org.). O currículo nos limiares do contemporâneo. Rio de Janeiro: DP\&A, p. 85-92, 2001.

MEYER, D. G. "Escola, currículo e diferença: implicações para a docência". In: BARBOSA, R. L. L. Formação de educadores: desafios e perspectivas. São Paulo, UNESP, p. 257-265, 2003.

PORTUGAL. Diário da República, 1. a série - n. 151 - 06 ago. 2009. Disponível em: http://dre.pt/pdf1s/2009/08/15100/0509705098.pdf. Acesso em: 23 set. 2011.

RIBEIRO, P. R. C. Inscrevendo a sexualidade: discursos e práticas de professoras das séries iniciais do Ensino Fundamental. 2002. Tese (Doutorado no Instituto de Ciências Básicas da Saúde) - Universidade Federal do Rio Grande do Sul, Porto Alegre. 2002.

RIBEIRO, P. R. C.; SOARES, G.; As identidades de gênero. In: RIBEIRO, P. R. C.; QUADRADO, R. (Org.). Corpos, Gêneros e Sexualidades: questões possíveis para o currículo escolar. 3. ed. Rio Grande: Editora da FURG, 2013.

SCOTT, J. W. "Gênero: Uma Categoria Útil para a Análise Histórica". Traduzido pela SOS: Corpo e Cidadania. Recife, 1990.

SOARES, G. Gravidez na Adolescência. In: Corpos, Gêneros e Sexualidades: questões possíveis para o currículo escolas. Organizador: RIBEIRO, P. R. C. e QUADRADO, R. P.; 3. ed. Rio Grande: Editora da FURG, p. 44-48, 2013.

TARDIF, M.; LESSARD; LAHAYE. Os professores face ao saber: Esboço de uma problemática do saber docente. Teoria \& Educação, n. 4, Porto Alegre: Pannônica, 1991.

UNESCO. Orientações técnicas de educação em sexualidade para o cenário brasileiro: tópicos e objetivos de aprendizagem. Brasília, p. 53. 2014.

VIANNA, C. P.; UNBEHAUM, S. O gênero nas políticas públicas de educação no Brasil: 1988-2002. Cad. Pesquisa, v. 34, n. 121, p. 77-104, 2004. 


\section{Como referenciar este artigo}

ARAUJO, Marilia Frassetto de; ROSSI, Célia Regina; TEIXEIRA, Filomena. O saber fazer docente em educação para a sexualidade na educação básica: um paralelo entre Portugal e Brasil. Revista Ibero-Americana de Estudos em Educação, Araraquara, v. 14, n. esp. 2, p. 1410-1426, jul., 2019. E-ISSN: 1982-5587. DOI: 10.21723/riaee.v14iesp.2.12608

Submetido em: 30/09/2018

Revisões requeridas: 20/02/2019

Aprovado em: 30/04/2019

Publicado em: 26/06/2019 